\title{
Why it is so difficult for persons with schizophrenia living in the community to achieve an adequate quality of life
}

\author{
HEINZ KATSCHNIG
}

\section{HAPPINESS AND QUALITY OF LIFE}

Myers \& Diener (1996) in collating data from almost 1000 surveys of 1.1 million people around the globe found that - contrary to what psychiatrists might think most people are happy and satisfied with their lives. In fact, on a zero to ten scale (with 0 meaning most unhappy and ten most happy) the modal value was between 7 and 8. What is even more surprising is that most sociodemographic variables, which usually make a difference when mental disorders are considered, do not seem to be related to the degree of happiness. These variables include sex, age, economic class, ethnicity and educational level, with the notable exception of marital status with the married being more happy than the never married.

Possible explanations for these astonishing findings are that people in disadvantaged situations might value things at which they excel, make comparisons within their own group and, speaking more generally, lower their level of aspiration. The last of these explanation is in accordance with Calman's (1984) definition of a person's subjective quality of life, which he considers to be equivalent to the narrowness of the gap between a person's expectations and achievements ('Calman's gap'). There are two ways of keeping this gap narrow: being successful in arriving at one's aims on the one hand, and lowering one's level of aspiration on the other. It is quite obvious that, in view of the low chance for most people to change their life circumstances to a substantial degree, the second mechanism is the most commonly employed in order to maintain their psychological equilibrium. People cut their coat to their cloth. The fable of the fox and the grapes is precisely reflecting this idea.

\section{QUALITY OF LIFE IN SCHIZOPHRENIA}

Lowering one's expectations also seems to be a mechanism preferred by schizophrenic patients living in the community, in order to maintain self-esteem and subjective well-being. While the subjectively assessed quality of life of schizophrenic patients living in the community is mostly lower than that of healthy control groups of the general population, it is quite surprising how many of these patients are satisfied, when they assess their quality of life with quantitative scales of subjective wellbeing (Lehman et al., 1982). Some studies even find no differences to the general population (e.g. Larson \& Gerlach, 1996).

It is surprising that some sociodemographic variables (e.g. economic status and age), already discussed as being of low value for predicting subjective quality of life in the general population, also do not seem to correlate with the subjectively reported quality of life of schizophrenic patients living in the community (Bobes \& Gonzales, 1997). Low educational level, however, is more consistently related to a better quality of life, as well as female sex is. Positive affect and a sense of personal control and empowerment tend to improve quality of life, while perceived stigma is related to a lower quality of life (Mechanic, 1997). If negative symptoms and extrapyramidal side effects are present, subjective quality of life is usually poorer (Meltzer et al., 1990). It is notable that standard of living and housing do not seem to be as important for schizophrenic patients' quality of life as they are for healthy persons (Skantze et al., 1990; Barry, 1997).

Most results discussed so far originate in studies using

Indirizzo per la corrispondenza: Professor H. Katsching, Department of Psychiatry, University of Vienna, Währingergürtel 18-20, 2-1090 Vienna (Austria).

Fax: +43-1-40400.3605 
quantitative evaluations of subjective quality of life, well-being and satisfaction. As Barry (1997) states, the existing global scales, designed for use in the general population, may not always be appropriate for the mentally ill. In fact, when qualitative methods are employed, dissatisfaction with many aspects of life becomes apparent (Barham \& Hayward, 1991).

Three fields are identified here, which may contribute to the difficulties of schizophrenic patients to achieve an adequate quality of life: (1) It is obvious that schizophrenic patients living in the community have additional needs and fewer personal and environmental resources than healthy persons. (2) They have a serious needs dilemma due to the stigma attached to schizophrenia, and (3) they have occasional difficulties in adequately identifying and expressing their needs and assessing their quality of life.

\section{SCHIZOPHRENIC PATIENTS HAVE ADDITIONAL NEEDS AND FEWER PERSONAL AND ENVIRONMENTAL RESOURCES}

Maslow (1954) has put forward an intuitive but useful taxonomy of human needs, which is actually embedded in a hierarchy. It includes, as the most basic of all human needs, physiological needs (like food), then safety needs, belonging needs, esteem needs and, finally, self-actualisation needs, which include the need for autonomy. While the more basic needs for food and shelter have been clearly better fulfilled in the setting of the mental hospital than in community settings, esteem and self-actualisation needs have not - they have a greater chance of realisation in community settings, where the fulfilment of the more basic needs is less guaranteed. Belonging needs have an ambiguous status in both settings.

Trying to fulfil these needs is especially difficult for schizophrenic patients, because they have additional disease-related needs, which normal people don't have, and because of their deficiencies in personal and environmental resources. The disease specific additional needs are mainly due to the symptoms and comprise the need for specific psychological coping skills or medication to control the symptoms. In addition, schizophrenic patients' specific vulnerability and sensitivity to stress requires an accepting and uncritical environment. And their sensitivity to understimulation leads to a need for optimal stimulation and a structured psychosocial environment. The latter two are difficult to find in natural environments. The deficiencies in per- sonal resources comprise the lack of daily living ski Is, of social skills and of cognitive skills. Environment deficiencies include mainly the lack of an adequate di structure, due to the lack of an adequate job, and $p$ verty. One of the most consistently expressed need that for money - money can buy autonomy!

\section{NEEDS DILEMMA DUE TO STIGMA}

It becomes especially apparent in qualitative studi that patients discharged from mental hospitals and su fering from persistent mental illness have to fight agai st social exclusion. They clearly "want to be one of $u$ (Barham \& Hayward, 1991). This is a reflection of tl natural belonging need $s$ of all human beings.

They dislike the stigma of mental illness, which e cludes them from social life. These patients are subje to many different kinds of formal and informal discı minations. Also, patients clearly understand the prej dice the general population has towards the mentally $i$ especially concerning their assumed dangerousness at unpredictability - after all they once belonged to this $\mathrm{g}$ neral population and they know that they once had th ses very prejudices themselves.

In this respect psychiatric patients have to choo between two no-win situations: Either they accept t] stigma, in identifying themselves with the role of the ps chiatric patient and declaring themselves as psychiatr patients; by this they are entitled to professional suppc in order to have basic medical and material needs $\mathrm{ft}$ filled (by receiving treatment. care, social benefits etc Or, they refuse to accept the role of the psychiatric $p$ tient for the sake of not being excluded from normal s cial contacts and keeping their autonomy, but give । their right to get organised support, which could help p tients to improve their quality of life. The tragedy is, th many of these patients are not able to maintain norm social roles, and are finally discriminated and stigmal zed in the same way as the patients described in the $f$ st group. Probably many homeless psychiatric patien belong to this second group.

Whichever strategy is chosen by a patient, it is o vious that both stigma acceptance and stigma avoida ce are irritating and energy consuming processes, wr ch further reduce the chance of achieving an adequa quality of life. 


\section{OCCASIONAL DIFFICULTIES IN ADEQUA- TELY PERCEIVING AND COMMUNICATING NEEDS}

While in somatic medicine usually no doubts are raised, whether patients are in a position to adequately evaluate their quality of life, such doubts have come forward in relation to psychiatric disorders. However, it is quite clear that psychiatric patients are able to make reasonable judgements about their quality of life most of the time (Lehman, 1983a, b), and that only during episodes of more severe psychopathology this ability may be impaired.

However, it is important to identify such periods and to be cautious in prematurely drawing conclusions from quality of life data collected during such periods. There are three types of symptoms, which can distort subjective quality of life assessments: affective, cognitive and reality distortion symptoms, such as delusions and hallucinations. The respective distortions of quality of life measures, have been called the affective, the cognitive and the reality distortion fallacy (Katschnig, 1997).

Depression - often a concomitant feature of schizophrenia - is related to a negative cognitive set of viewing the self, the word and the future (Beck, 1976). It is clear that a depressed person will also assess his quality of life negatively, he usually sees his well-being, social functioning and living conditions as worse than an independent observer (Kay et al., 1964), or even than himself, if he looks back after recovery (Morgado et al., 1991). The opposite is true for conditions of elevated mood. That cognitive dysfunction prevents an adequate subjective assessment of quality of life is quite obvious. The same applies to hallucinations and delusions.

One other problem schizophrenic patients have in adequately expressing their needs concerns the downward adaptation of aspirations, if the disorder has lasted for some time. This mechanism is not specific to schizophrenia, but also applies to many somatic chronic conditions. The standards, which a person once wanted to achieve, drift downwards until the distance between aspirations and achievements is sustainable. In this situation, as well as in the case of the three psychopathological fallacies, external assessments of quality of life by professionals and significant others is appropriate. Becker \& Diamond (1997) have developed a quality of life instrument (the Wisconsin Quality of Life Index, W-QLI) which takes care of this approach by providing a carer and professional as well as a patient version. Sainfort $e t$ al. (1996) have demonstrated that this approach is useful in schizophrenia.

\section{CONCLUSION}

A person's quality of life should not only be defined by a person's subjective sense of well-being, but also by the ability to function in various life domains, and by the possibility to access resources and opportunities (Katschnig, 1997; Lehman, 1997). While subjective wellbeing and happiness might seem to be the ultimate goal all people are striving for, functioning in social roles and access to resources and opportunities are the prerequisite for the possibility that such well-being and happiness can also be present in the future. For persons with persistent schizophrenia living in the community, we are obliged to help them to find an appropriate balance between lowering their expectations and increasing their achievements. In order to be able to help in an adequate way, subjective quality of life measures and measures of wellbeing and satisfaction, should therefore be supplemented by objective measures of functioning in social roles and access to environmental resources. Qualitative methods should be used alongside the traditional quantitative approach.

\section{REFERENCES}

Barham M. M. \& Hayward R. (1991). From the Mental Patient to the Person. Routledge: London.

Barry M. M. (1997). Well-being and life satisfaction as components of quality of life in mental disorders. In Quality of Life in Mental Disorders (ed. H. Katschnig, H. Freeman and N. Sartorius), pp. 3142. John Wiley \& Sons: New York.

Beck A. T. (1976). Cognitive Therapy and the Emotional Disorders. International Universities Press: New York.

Becker M. \& Diamond R. (1997). New developments in quality of life measurement in schizophrenia. In Quality of Life in Mental Disorders (ed. H. Katschnig, H. Freeman and N. Sartorius), pp. 119133. John Wiley \& Sons: New York.

Bobes J. \& Gonzales M. P. (1997). Quality of life in schizophrenia. In Quality of Life in Mental Disorders (ed. H. Katschnig, H. Freeman and N. Sartorius), pp. 165-178. John Wiley \& Sons: New York.

Calman K. C. (1984). Quality of life in cancer patients - an hypothesis. Journal of Medical Ethics 10, 124-127.

Katschnig H. (1997). How useful is the concept of quality of life in psychiatry? In Quality of Life in Mental Disorders (ed. H. Katschnig, H. Freeman and N. Sartorius), pp. 3-16. John Wiley \& Sons: New York.

Kay D.W.K., Beamisch P. \& Roth M. (1964). Old age mental disorders in Newcastle-upon-Tyne, II. A study of possible social and medical causes. British Journal of Psychiatry 110, 668-682.

Larson E.B. \& Gerlach J. (1996). Subjective experience of treatment, side-effects, mental state and quality of life in chronic schizophrenic out-patients treated with depot neuroleptics. Acta Psychiatrica Scandinavica 93, 381-388.

Lehman A.F. (1983a). The well-being of chronic mental patients: assessing their quality of life. Archives of General Psychiary 40, 369-373. 


\section{H. Katschnig}

Lehman A.F. (1983b). The effects of psychiatric symptoms on quality of life assessments among the chronically mentally ill. Evaluation and Program Planning 33, 299-315.

Lehman A.F. (1997) Instruments for measuring quality of life in mental illness. In Quality of Life in Mental Disorders (ed. H. Katschnig, H. Freeman and N. Sartorius), pp. 79-94. John Wiley \& Sons: New York.

Lehman A.F., Ward N.C. \& Linn L.S. (1982). Chronic mental patients: the quality of life issue. American Joumal of Psychiatry 139, 1271-1276.

Maslow A.H. (1954). Motivation and Personality. Harper \& Row: New York.

Mechanic D. (1997). Organisation of care and quality of life of persons with serious and persistent metal illness. In Quality of Life in Mental Disorders (ed. H. Katschnig, H. Freeman and N. Sartorius), pp. 305-317. John Wiley \& Sons: New York.
Meltzer H.Y., Burnett S., Bastani B. \& Ramirez L.F. (1990). Effects of six months of clozapine treatment on the quality of chronic schizophrenic patients. Hospital Community in Psychiatry 141, 74-76.

Morgado A., Smith M., Lecrubier Y. \& Widlocher D. (1991). Depressed subjects unwittingly overreport poor social adjustment which they reappraise when recovered. Journal of Nervous and Mental Disease 179, 614-619.

Myers D.G. \& Diener E. (1996). The pursuit of happiness. Scientific American May, 54-56.

Sainfort F., Becker M. \& Diamond R. (1996). Judgements of quality of life of individuals with severe mental disorders patient self-report versus provider perspectives. American Journal of Psychiatry $153,497-502$

Skantze K., Malm U., Dencker S.J. \& May P. R. (1990). Quality of life in schizophrenia. Nordisk Psykiatrisk Tidsskrift 44, 71-75. 